stood, amongst even the intelligent public, that the scientific study of disease can be effectively accomplished only at the outlay of much time and money. It is gratifying, therefore, to find that in the ably written article on the outbreak of rat plague in Suffolk, which appeared in The Times of December 22, I910, the writer emphasises this point with refreshing candour. He insists that in a crisis of this kind, the effort to cope with the situation must be a national one, and that the Government must authorise the expenditure of ample funds to provide for the establishment of a staff of experienced investigators and administrators to deal with the problem. The history of the organisation of plague measures gives ample proof of the futility of adopting plans, however vigorous, that are not based on clear conceptions of the disease gained by scientific research.

\section{WHAT SCIENCE HAS DONE FOR THE WEST INDIES.}

A LITTLE more than a year ago $I$ told in these $A$ pages, with a very sore heart, the story of what the late Sir Alfred Jones had accomplished for the West Indies by enlightened commercial methods. That chapter is unhappily closed, for no one has succeeded him. It is a more hopeful task which is now imposed upon me-to give some account of what science has done, and will continue to do. It is worth the telling, and it is more than a mere record of success, but carries a moral of far-reaching extent.

This journal, from its first number, has never ceased to preach the necessity of applying knowledge to the right conduct of human affairs. It continues to preach, and in face of the stolid conservatism of our methods, one might in a despondent mood think with little effect. But if one looks back over long periods it is not so, and the change in public opinion as represented by governmental action is little short of astonishing.

When I first became engaged in colonial work some forty years ago, the doctrine of laissez faire was in full swing. It was held that self-interest would determine whether an industry would succeed or fail; if it failed it deserved to do so, and another would take its place. In either case it was best to leave it severely alone. This is not the place to discuss how far such a doctrine is sound. But practically it is continually being abandoned. No industry is now free from governmental interference, and such interference is only tolerable if directed bv adequate technical knowledge. Interference must always be of the nature of restraint, and at any rate theoretically one mav ask whether some compensation is not justified. It can hardly be doubted that the community will have more and more to provide knowledge for industry of the kind that self-interest is powerless to provide for itself.

Mill, however, and other economists clearly saw that academic economic principles were not universally applicable to agriculture. The reason is obvious : the soil is not removable, but has to be utilised as best it can, and where it is. If it went generally out of cultivation food would fail. It was still, however, left to laissez faire, except in some measure in India, where the Grovernment undertook the pioneering work in regard to tea, cinchona, rubber, and some other staples, and then left their commercial development to private individuals. In any other country but our own the work of Rothamsted would have been promoted by the State. There are undoubtedly advantages in scientific research being left unfettered to individual effort, but it is only the richest landowners, such as Coke of Holkham, and the Dukes of Bedford, NO. 2 I 54 , VOL. 85$]$ who can afford to add to agricultural knowledge by experiment. The average cultivator is powerless to follow other than traditional methods. Yet it is in the interest of the community that he should do better in order that the maximum return may be obtained from the land.

When this country began to acquire tropical possessions, it was seen, however, that something more than laissez faire was required for their economic development. It was the Royal Society, at the hands of its president, Sir Joseph Banks, who first took the work in hand. Having the ear of the King, he was able to use Kew, which was then the private property of the Royal Family, for the purpose. The mutiny of the Bounty was an incident in an attempt to add to the cultural resources of the West Indies. An indirect result was the foundation of the great Dutch colonial botanical establishment at Buitenzorg. When it was decided that Kew should be maintained as a national establishment, its colonial utility was apparently one of the main reasons for the decision. In a scheme which received the sanction of Parliament the interests of "commerce" and "agriculture" were recognised, as well as the supply "of authentic and official information on points connected with the foundation of new colonies." Its functions in this respect were steadily fostered by the Hookers, father and son. The history of Kew thus affords one of the earliest instances in this country of the recognition of the duty of the State to promote scientific knowledge in the public interest. And the historic meaning of the controversies which have occasionally brought Kew prominently into public notice is simply the attempt of a policy of laissez faire to arrest its work.

But anything which is rooted in sound principles cannot be checked, because their necessity insists on asserting itself; and the West Indies again supply the illustration. Obviously their chief asset is solar energy. Our channel islands supply us with early vegetables. In a rule-of-three sum the West Indies stand for the channel islands of the North Atlantic shores. Alfred Jones saw this, and started a line of steamers to flood us with West Indian fruit. But this is anticipating. In the nineties their condition was the reverse of prosperous. And, if it is a paradox that science was indirectly the cause of the mischief, it happily was able to supply the remedy.

The Napoleonic empire left behind it two permanent legacies-the French code and beetroot sugar. When Napoleon's continental system closed the ports of Europe to British colonial produce, the import of tropical sugar was cut off. As sugar is a necessity of modern food there was the strongest impulse to find a new supply. I need not repeat a well-worn story. The chemist and the cultivator lavished all their resources on the unpromising beet, and ultimately dethroned the sugar-cane. Then came the bounties which flooded this country with sugar at scarcely more than cost price, and drove cane-sugar out of consumption.

There is a fundamental principle in agriculture: never to trust to a single crop. Ireland trusted to the potato and Ceylon to coffee, and both failed them; this was from disease. The West Indies trusted to sugar, and in their case the ruin was economic. The balance of solar energy being in its favour, on equal terms the cane should at least hold its own with the beet. But now comes the mistake and its moral. The sugar content of the cane was held to be incapable of increase; the methods of manufacture were often archaic and wasteful. Beetroot-sugar was the product of the most refined scientific skill in both directions. It was the fable of the hare and the tortoise. 
In the 'nineties then the West Indies had sunk from prosperity to poverty. I heard it publicly stated at a meeting in the City of London that annexation to the United States was the only remedy. On some of the islands the peasantry were clamouring for food. And so things might have remained but for Mr. Chamberlain, who has never hesitated to cut himself adrift from hide-bound prejudices, and, regardless of them, to apply a practical remedy to an evil.

In 1897 , after obtaining from Parliament some temporary relief, he sent out a commission of inquiry, of which Sir Edward Grey was a member, and to which Sir Daniel Morris, then assistant director of Kew, was attached as secretary. The Imperial Department of Agriculture was established the following year, and Sir Daniel Morris left Kew to take up the duties of commissioner. In a recent paper before the Royal Colonial Institute (see Nature, January 26) he has given a full, and I think extremely modest, account of what he was able to achieve. That paper will speak for itself. My purpose is to show how success flowed from the patient and persistent application of scientific method.

The first thing was to see if the sugar-content of the cane could be improved. Like many other plants subjected to long cultivation, it was believed to have lost the power of producing seeds. The Pacific Islands had been ransacked without much success to find more productive kinds which might have arisen possibly by bud-variation. The White Transparent cane, which is regarded as a standard in the West Indies, yields $2 \frac{1}{4}$ tons of sugar to the acre. As sugar-content varies, like everything else, in individual plants, it was suggested from Kew that an improved race might be obtained by the process of chemical selection by which the Vilmorins worked up the beet to a high standard and maintain it at it. Some success was obtained, but it was evident that it would be extremely slow. By a stroke of good fortune a more rapid method was discovered. About 1888, Mr. Bovell and Prof. Harrison noticed the spontaneous occurrence of seedling sugar-canes in Barbados. It was found that the sugar-cane did actually produce seed, though in so small a quantity that it had been overlooked. As this at once opened the door to seminal variation and selection, the attention of the Colonial Office was at once directed by Kew to the importance of the discovery. The work was vigorously taken up by Sir Daniel Morris, and from 1908 onwards seedlings have been raised on a large scale by $\mathrm{Mr}$. Bovell, and continuouslv selected from, as well as hybridised.

The result has surpassed expectation. One seedling cane, for example, B. 3405 , gave an increase more than the standard of one ton an acre, representing a net profit of $\mathcal{E}^{8}$. Dr. Watts, the present commissioner, estimates that the benefit to Antigua and St. Kitts alone would more than cover the expense of the department. Much light has been thrown on the food requirements of the cane by carefully controlled experiment. As might be expected, potash is found to be favourable, but phosphatic manures to have involved monetary loss. Dr. Watts, who has been the pioneer in the promotion of central factories, has obtained an increased production of 40 per cent. more than the "Muscovado system." Nor is this all. The pests and diseases by which the sugar-cane, like all other cultivated plants, is attacked had to be combated. The Cambridge School was drawn upon for mycologists and entomologists. Mr. Maxwell-Lefroy achieved a notable success in discovering the means of controlling the destructive moth-borer.

The upshot is that a moribund industry has been given a new lease of life by bringing scientific method to bear upon it. Laissez faire would say that the NO. 2154 , VOL. 85 ] planters might have done it for themselves. But they did not, and, in fact, could not; a scientific campaign can no more be conducted by amateurs than a military one; the planters would not have known what positions to attack, nor could they have found the necessary men to do it nor directed them if they had.

Other industries had to be revived or created. Perhaps the most important of these was the production of Sea Island cotton with the generous help of the United States.

Lastly, but by no means least, an ethicient system of rural education has been organised for the negro peasantry. I have no hesitation in saying that it is far in advance of anything which exists in the county where I am writing.

And thus Sir Charles Lucas, speaking from the perspective of the Colonial Office, is able to say that "while the eighteenth century saw the greatness of the West Indies, the nineteenth their distress, the twentieth century, he hoped, would witness their regeneration."

But this is not the end of the story. What has been accomplished in the West Indies has not been without its effect as an object-lesson elsewhere. It is to the credit of the Government of India that it has been, as already remarked, in advance of its time in pioneering work. It deprived China of the monopoly of tea, and, with the help of Kew, it has created the rubber industry of the East. But except as regards forestry it has effected little in intensive cultivation.

Canning claimed that he brought the New World to redress the balance of the Old. The Department of Agriculture for the West Indies has stimulated a new activity in the East, where some of its trained officers have found a larger scope for work. The recently published "Report of the Board of Scientific Advice for India" shows an awakeness and initiative which would have been looked for in vain a dozen years ago. W. T. Thiselton-Dyer.

\section{PICTORIAL NATURAL HISTORY. ${ }^{1}$}

$\mathrm{I}$ this little book the experience of the expert photographer has been combined with that of the keen naturalist; the result is a volume full of interest to all lovers of the countryside. The publisher, in a special preface, directs attention to the unusually large number of illustrations, which are exclusively reproductions of photographs taken by the author. Mr. Douglas English's success with his camera has been demonstrated on many previous occasions, and in "A Book of Nimble Beasts" he certainly gives us of his best. There are a number of pictures in this volume which are probably unique, and the reader's special attention is directed to the remarkable series of photographs illustrating the life-history of the sand-wasp (Odynerus spinipes).

The somewhat clumsy title is apt to give the impression that Mr. English's book deals in the main with the higher animals; this is by no means the case, and, indeed, some of the best pictures and chapters deal with the lower forms of life.

The value of the illustrations is increased by the fact that all are brought closely into connection with the chapters which they illustrate, a somewhat rare quality for a book of this type.

As in many recent books dealing with nature-study, Mr. English's text consists of a series of short stories, in the course of which the characteristic habits of different animals are brought out with the utmost faithfulness, and it is a pleasure for the reviewer to record the absence of any irritating zoological errors such as " "A Book of Nimble Beasts." Bunny Rabbit, Squirrel, Toad anif "thoie sort of people." By D. English. Pp. 319. (London: Eveleigh Nash, 1910) Price 6s. net. 